\title{
The Quantitative Appraisal of Coronary Vascular Lesion in Experimental Hypertension and Hypercholesterolemia with Special Reference to Intramural Arteriolosclerosis
}

\author{
Jugoro TAKeughi, M.D., Akira Takada, M.D., Shuichiro \\ SAKaI, M.D., Keijiro Nishide, M.D., Nobuo \\ Ohya, M.D., and Kenji Kitamura, M.D.
}

\section{SUMMARY}

An attempt was made to investigate experimentally whether arteriolosclerosis in the myocardium was accelerated by concomitant arterial hypertension and/or hypercholesterolemia.

Young male albino rabbits were divided into 5 groups, i.e., hypertensive, hypertensive and hypercholesterolemic, normotensive and hypercholesterolemic, operated but normotensive and control group, respectively. Hypertension was induced by means of a modified Goldblatt's technique and hypercholesterolemia by feeding lanolin and cotton seed oil. To obtain the media/diameter ratio of small arteries and arterioles in the myocardium, the constricted and deformed vessels were stretched completely and the widths of the media and external diameter of corrected vessels were calculated geometrically. The frequency of the small vessels having the intimal changes was compared in each group.

The media/diameter ratios of small arteries and arterioles in the myocardium increased in the groups with hypertension and were not influenced by hypercholesterolemia. The media/diameter ratios in each rabbit declined linearly in 40 to $110 \mu$. of external diameter and did not show a specific increase. Endothelial hyperplasia and splitting and proliferation of the internal elastic lamina were the main intimal changes of the small myocardial arteries and arterioles in the rabbits which were not fed with lanolin and cotton seed oil. These intimal changes were found most frequently in the subendocardial regions of the left ventricles of hypertensive rabbits.

It was suggested that the medial changes of arterioles and small arteries in the myocardium were related to hypertension and the intimal changes were accelerated by hypertension but might not be primarily caused by hypertension.

From the First Department of Internal Medicine, School of Medicine, Kanazawa University, Kanazawa.

Received for publication July 22, 1968.

This work was supported in part by Research Grant No. 72043 administered by the Educational Ministry of Japan. 
Additional Indexing Words:

Media/diameter ratio Goldblatt operation Myocardium Blood pressure Lanolin Cotton seed oil Rabbit Arteriole Small artery Internal elastic lamina

7 XTENSIVE studies on etiology and pathogenesis of arterio- and arteriolosclerosis have been reported either in experimental animals with hypertension and/or hypercholesterolemia or in human autopsy materials. The progression of coronary arteriosclerosis is now generally accepted to be accelerated by concomitant arterial hypertension and/or hypercholesterolemia. ${ }^{11}$

Arteriolar changes in arterial hypertension have long been discussed and recognized to be not pathognomonic of arterial hypertension, but to be accelerated by hypertension. ${ }^{2,3)}$ They are frequently observed in selected organs such as the kidney, brain and spleen. Many studies have been reported on arteriolar changes in these organs, especially in the kidney. ${ }^{2}$ In the myocardium, however, few works involving quantitative evaluation of the changes in arteriolar architecture have been reported. ${ }^{4), 5)}$ A controversy exists whether, in the human heart, myocardial arteriolosclerosis is affected by hypertension or not. ${ }^{2,5)-20)}$ Thus an attempt was made to investigate whether sclerosis of small arteries and arterioles in the myocardium was accelerated by hypertension and/or hypercholesterolemia in the experimental animal.

\section{Materials and Methods}

Maintenance of experimental animals: Young male albino rabbits, weighing 1.5 to $2.0 \mathrm{Kg}$., were fed with a commercial ration for rabbits (Oriental Yeast Industrial Co., RC 5 ; about $150 \mathrm{Gm}$./day) with water ad libitum during the earlier period of the experiment and later with vegetables (about $400 \mathrm{Gm}$./day) and Okara (about $300 \mathrm{Gm} . /$ day) without water, i.e., the remnant of soy bean curd (composition of Okara: protein $3.5 \%$, fat $1.9 \%$, carbohydrate $6.9 \%$, water $84.5 \%$ ). No particular salt was added to the diets.

Measurement of blood pressure: Systolic blood pressure was measured with a rabbit in non-restricted state in the right midear artery by a hemodynamometer devised by Kawaguchi. ${ }^{10}$ For recordings of blood pressure, measurements were made repeatedly for several min. until the pressure reached stable value, and then the mean value of 3 consecutive recordings was recorded as the pressure at each experimental period. Blood pressure in each rabbit was recorded once or twice a week during the experiment.

Grouping of experimental animals: Fifty-eight rabbits were used for this experiment. Forty-one rabbits were operated on, 15 out of which died of operation or infection after operation. Twenty-four rabbits among 26 successfully operated on were divided into groups $A, B$ and $D$. Sixteen rabbits which were not operated on, except one which died of unknown etiology, were divided into groups $\mathrm{C}$ and $\mathrm{E}$.

Group A (hypertensive group; 7 rabbits): The rabbits in this group received a 
modified Goldblatt operation; the right renal artery was constricted with a silver clip of $0.5 \mathrm{~mm}$. in inner diameter and 7 to 30 days later the left renal artery was constricted with a clip of $0.8 \mathrm{~mm}$. in inner diameter. The rabbits showed an increase over $50 \mathrm{~mm} . \mathrm{Hg}$ in the postoperative maximum blood pressure compared to preoperative average blood pressure. The difference between average preoperative blood pressure and maximum postoperative blood pressure ranged from 54 to $114 \mathrm{~mm}$. Hg with an average of $77.0 \pm 18.7$ (S. D.) $\mathrm{mm}$. Hg.

Group B (hypertensive and hypercholesterolemic group; 8 rabbits): The rabbits in this group received the same operation as in group A with an increase of postoperative blood pressure over $50 \mathrm{~mm}$. $\mathrm{Hg}$ and were fed with $5 \mathrm{Gm}$. of lanolin and $3 \mathrm{ml}$. of cotton seed oil per day starting 3 to 20 days after the second operation. The difference between average preoperative blood pressure and maximum postoperative blood pressure in this group ranged from 61 to $115 \mathrm{~mm}$. $\mathrm{Hg}$ with an average of $92.5 \pm 15.4 \mathrm{~mm} . \mathrm{Hg}$.

Group $\mathrm{C}$ (normotensive and hypercholesterolemic group; 9 rabbits): The rabbits were fed with lanolin and cotton seed oil in the same manner as in group B, but did not receive the operation.

Group D (operated but normotensive group; 9 rabbits): The rabbits, which, in spite of constriction of the left or bilateral renal arteries, did not show any significant increase in postoperative blood pressure during their lives, were included in this group. The difference between average preoperative blood pressure and maximum postoperative blood pressure ranged from 29 to $42 \mathrm{~mm}$. Hg with an average of $33.4 \pm 4.6 \mathrm{~mm}$. Hg.

Group E (control group; 7 rabbits): The rabbits were neither operated on nor given lanolin and cotton seed oil.

Two rabbits which were operated on and fed with lanolin and cotton seed oil were not classified into any group, because they did not show a significant increase in postoperative blood pressure.

Staining of sections: The rabbits were sacrificed by the intravenous administration of thiopental sodium at the various intervals of 1 to 11 months. In group A, 1 rabbit was sacrificed at 2 months, 2 at 3 months, 2 at 7 months, 2 at 9 months, after the completion of surgical procedure ; in group B, 3 rabbits at 3 months, 2 at 4 months, 1 at 5 months, 2 at 6 months, after the second operation ; in group C, 1 rabbit after 2 months maintenance, 3 at 3 months, 3 at 4 months, 2 at 7 months; in group D, 3 rabbits at 1 month after the operation, 2 at 2 months, 2 at 4 months, 1 at 6 months, 1 at 11 months; in group E, 2 rabbits after 2 months maintenance, 2 at 3 months, 2 at 6 months, 1 at 10 months. The heart was removed as quickly as possible, fixed in $10 \%$ formalin, and cut into 10 to 13 small specimens ( 4 to 5 specimens from the left ventricle, 3 to 4 specimens from the right ventricle and 3 to 4 specimens from the interventricular septum). Four hearts obtained from 1 rabbit in group A, 1 in group $\mathrm{D}$ and 2 in group $\mathrm{E}$, could not be embedded in paraffin because of overdehydration of the tissue. The specimens of 36 hearts embedded in paraffin were cut in 2 different directions; one was vertical to the baso-apical axis in most specimens and the other was parallel to the epicardium in a specimen from the left ventricle. Each section was stained by Elastica Van Gieson's method, hematoxylin-eosin and azan stains.

Measurement of the media diameter: The sections stained by Elastica Van Gieson's method were magnified a thousand times by means of a microscope projector. 
For the measurements, the vessels which were cut vertically in thier direction were selected and their adventitia, endothelium and internal elastic lamina were traced onto paper. The area of the media and intima and the length of the internal elastic lamina on the papers were measured with a planimeter and a curvimeter, respectively, and the mean values of 2 consecutive measurements were recorded. To obtain the media/diameter ratio of each vessel, the constricted and deformed vessels were corrected to take a round form in which internal elastic laminae were stretched completely and widths of the media and external diameter of corrected vessels were calculated geometrically as shown in Fig. 1. The diameters of the calculated vessels ranged between 30 and $500 \mu$, and most of them were within the range of 30 to $150 \mu$.

The media/diameter ratio in each group was evaluated statistically by analysis of variance in 5 randomly selected cases from each group.

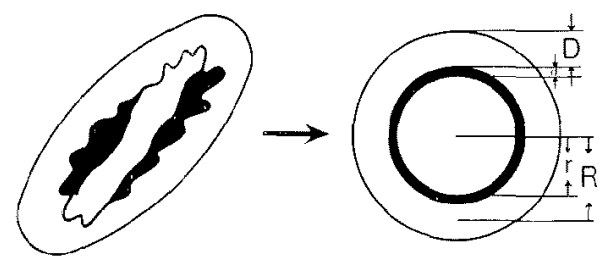

Area of media: $S$

Area of intima: $s$

Length of the internal elastic lamina: $\mathbf{L}$

$$
\begin{array}{rlrl}
\mathrm{D}= & \sqrt{\mathrm{L}^{2}+4 \pi \mathrm{S}}-\mathrm{L} & \mathrm{d} & =\frac{\mathrm{L}-\sqrt{\mathrm{L}^{2}-4 \pi \mathrm{s}}}{2 \pi} \\
\mathrm{R}=\frac{\mathrm{S}}{\sqrt{\mathrm{L}+4 \pi \mathrm{S}}-\mathrm{L}} & \mathrm{r} & =\frac{\mathrm{s}}{\mathrm{L}-\sqrt{\mathrm{L}^{2}-4 \pi \mathrm{s}}} \\
\text { media/diameter } & \text { ratio } & =\frac{2 \mathrm{D}}{2 \mathrm{R}+\mathrm{D}} \\
\text { wall/diameter } & \text { ratio } & =\frac{2(\mathrm{R}+\mathrm{d})}{2 \mathrm{R}+\mathrm{D}}
\end{array}
$$

Fig. 1. The method of determining the media/diameter.

\section{Results}

Fig. 2 shows the serial blood pressure recording in the 5 groups of rabbits. Fig. 3 and 4 show the media/diameter ratios under $50 \mu$. and 51 to $100 \mu$. in external diameter in each group, respectively. The mcdia/diameter ratios in groups $\mathrm{A}$ and $\mathrm{B}$ were significantly higher than in group $\mathrm{E}$ (between group $\mathrm{A}$ and group $\mathrm{E} ; p<0.01$, between group $\mathrm{B}$ and group $\mathrm{E} ; p<0.01$ ), and the ratios in group $\mathrm{E}$ werc not higher than in groups $\mathrm{C}$ and $\mathrm{D}$ (between group $\mathrm{E}$ and group $\mathrm{C} ; p>0.05$, between group $\mathrm{E}$ and group $\mathrm{D} ; p>0.05$ ). There was no difference in the thickness of the media between groups $A$ and $B(p>0.05)$. In order to compare the differences of the media/diameter ratios 


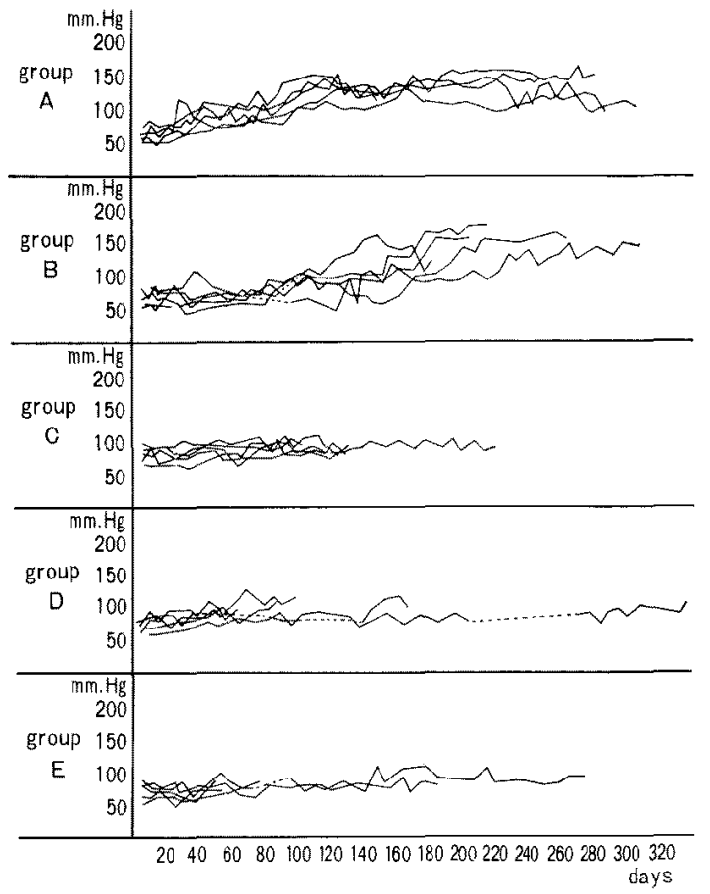

Fig. 2, Blood pressure recordings.

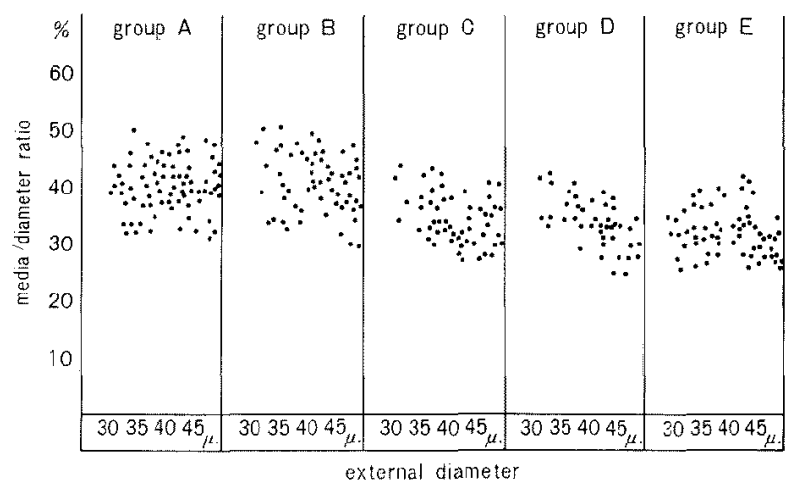

Fig. 3. The media/diameter ratios in the vessels under $50 \mu$. in external diameter.

among 5 groups more precisely, the vascular profile chart ${ }^{11)}$ was studied. According to the profile method, the external diameters of the arteries and arterioles were plotted along the horizontal axis with logarithmic scale and the media/diameter ratios were plotted along the vertical axis with an arithmetric scale for each rabbit. Fig. 5 shows the results obtained from representative cases in each group. In most rabbits, the profile chart showed a linear decline 


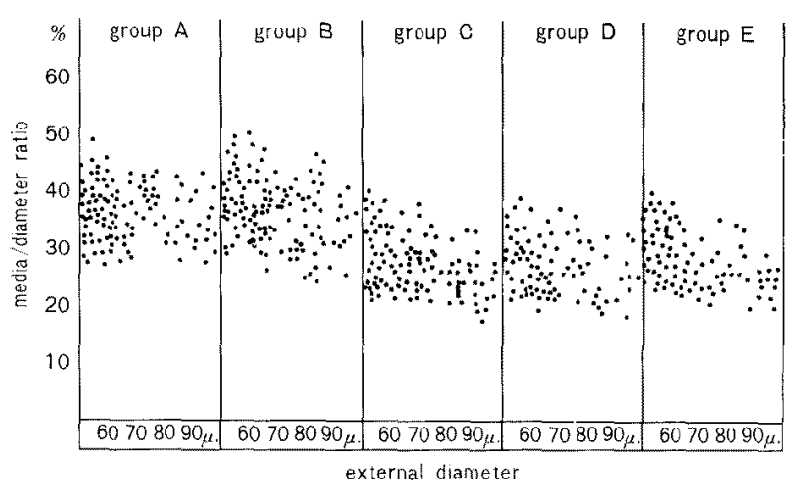

Fig. 4. The media/diameter ratios in the vessels from 51 to $100 \mu$. in external diameter.

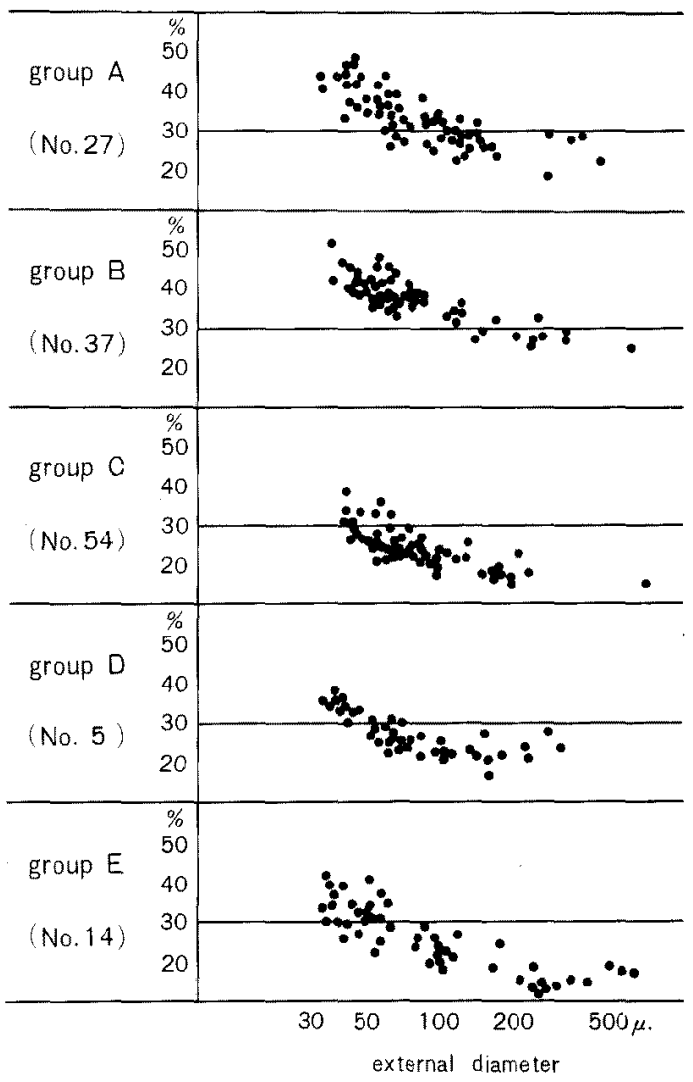

Fig. 5. Vascular profile chart of a case in each group.

in 40 to $110 \mu$. of external diameter and then a gentle upward tendency. The regression lines for the linear portion on the profile chart were calculated by the least square method in each rabbit. In this calculation, the vessels having 


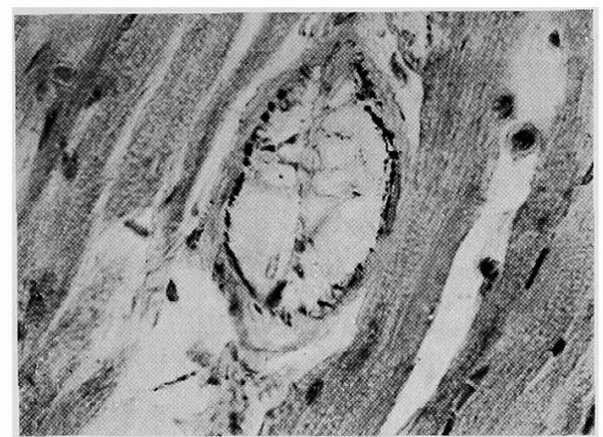

Fig. 6. The lumen is completely obstructed by foam cells. Partial swelling of internal elastic lamina is noted. The width of the media is very decreased. Elastica Van Gieson's stain ; $\times 690$.
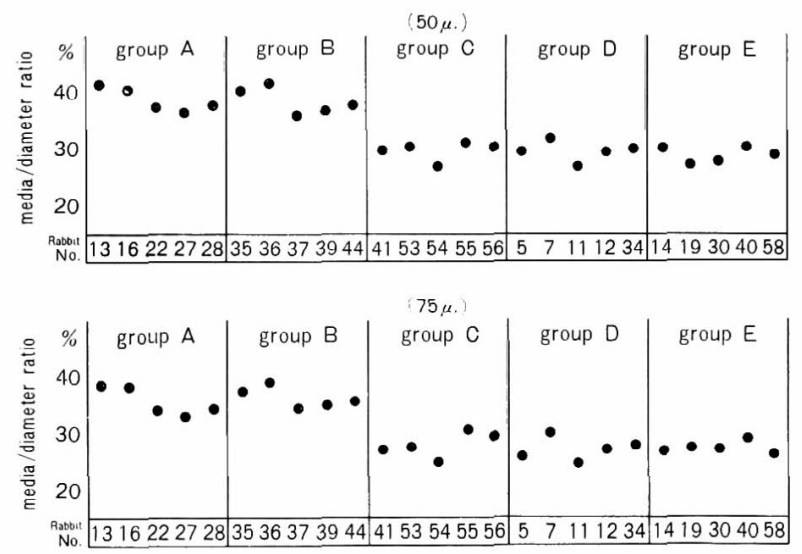

Fig. 7. The media/diameter ratio in the vessels of 50 and $75 \mu$. in external diameter on the regression lines.

severe intimal changes were not included since there was noticed some influence of intimal changes on the media (Fig. 6). The regression lines were not obtained from one rabbit in group A, 2 in group B and 2 in group D, in which few vessels were obtained which were cut vertically to their direction in 40 to $110 \mu$. of external diameter.

The regression lines were calculated for 5 rabbits in group A, 6 in group B, 7 in group C, 6 in group D and 5 in group E. The media/diameter ratios of 50 and $75 \mu$. in external diameter on these regression lines are shown in Fig. 7. Groups $A$ and $B$ had higher ratios than group $E$ in both of these 2 diameters (between group A and group E; $50 \mu . p<0.01,75 \mu . \quad p<0.01$, between group $\mathrm{B}$ and group $\mathrm{E} ; 50 \mu . \quad p<0.10,75 \mu . \quad p<0.01)$. No difference in the media/diameter ratios was observed among groups $\mathrm{C}, \mathrm{D}$ and $\mathrm{E}$ (between groups $\mathrm{C}$ and $\mathrm{E} ; 50 \mu . \quad p>0.05,75 \mu . \quad p>0.05$, between groups $\mathrm{D}$ and $\mathrm{E}$; 

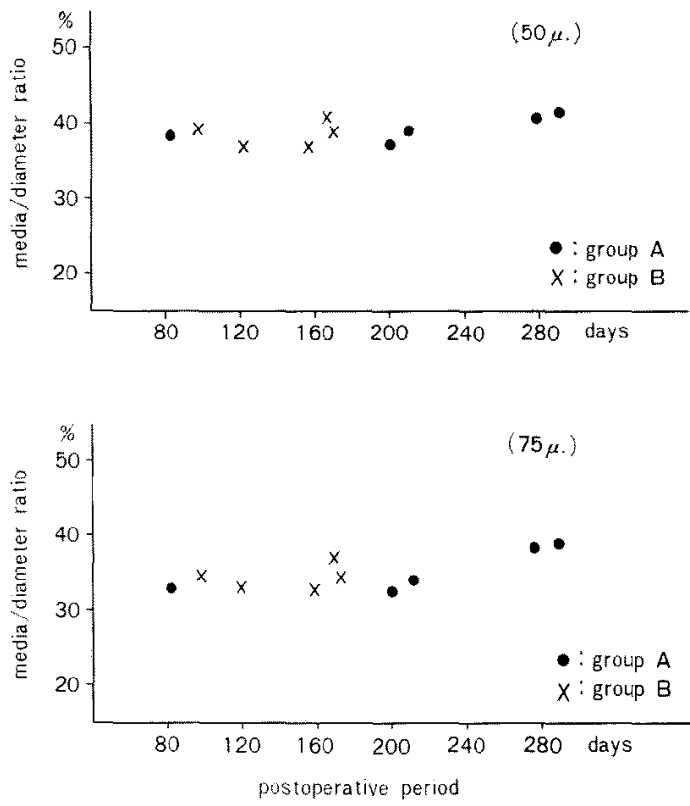

Fig. 8. The rnedia/diameter ratio and postoperative period of hypertensive rabbits.
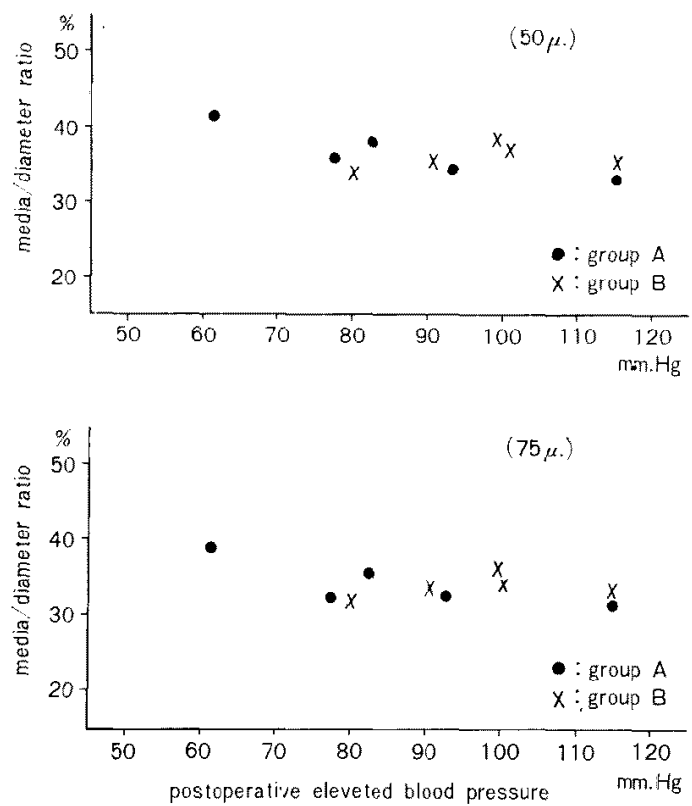

Fig. 9. The media/diameter ratio and postoperative elevated blood pressure in the vessels of 50 and $75 \mu$ in external diameter. 
$50 \mu . \quad p>0.05,75 \mu . \quad p>0.05)$.

The media/diameter ratios on the regression lines of groups $\mathrm{A}$ and $\mathrm{B}$ did not correlate with the duration of the postoperative period (Fig. 8, $p>0.10$ ), and with the degree of hypertension (Fig. 9, $p>0.10$ ). No correlation was found between the duration of observation and the media/diameter ratios in groups C, D and E (Fig. 10, $p>0.10$ ).

Endothelial hyperplasia and splitting and proliferation of the internal elastic lamina were the main intimal changes of the small myocardial arteries and arterioles in the rabbits which were not fed with lanolin and cotton seed oil (Fig. 11, 12). These intimal changes were found to some extent even in the normotensive groups (groups $\mathrm{D}$ and $\mathrm{E}$ ). However, these changes were most
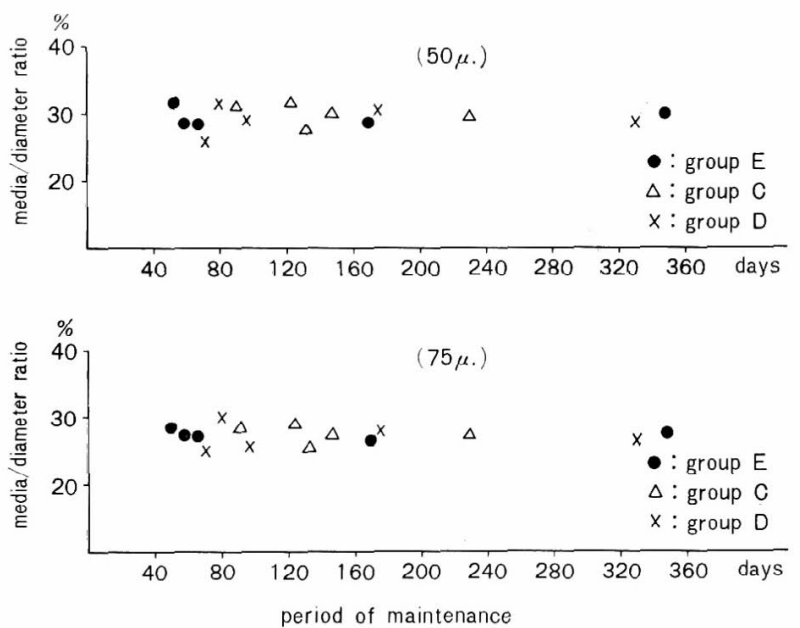

Fig. 10. The media/diamter ratio and the period of maintenance of nonhypertensive rabbits.

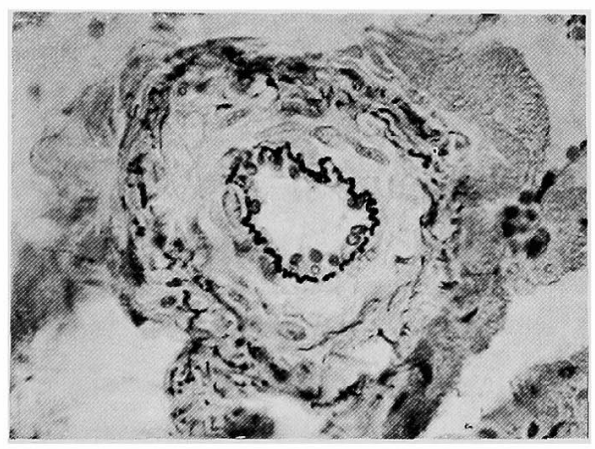

Fig. 11. Thickening of the media is evident and the medial nuclei increased in number. Segmentation and partial swelling of internal elastic lamina and slight intimal hyperplasia are noted. Elastica Van Gieson's stain; $\times 690$. 


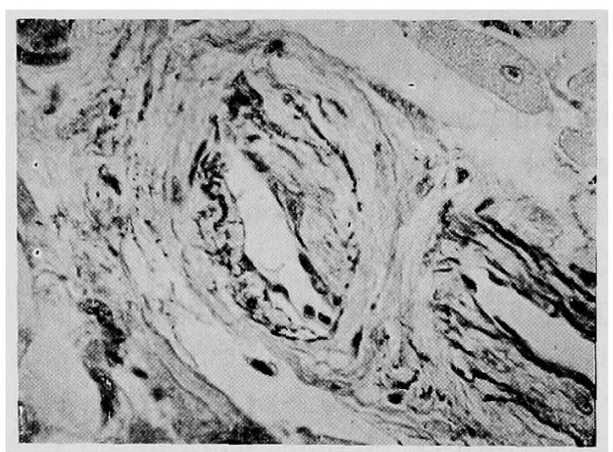

Fig. 12. Intimal hyperplasia and splitting and proliferation of internal elastic lamina are prominent. The width of the media decreased. Elastica Van Gieson's stain; $\times 690$.

Table I. The Frequency of Vessels Having Intimal Changes

\begin{tabular}{c|l|c|c|c}
\hline & & Left ventricle & $\begin{array}{c}\text { Interventricular } \\
\text { septum }\end{array}$ & Right ventricle \\
\hline $\begin{array}{c}\text { Group } \\
\text { A }\end{array}$ & Subepicardial region & $118(1)$ & $80(10)$ & $79(0)$ \\
\hline $\begin{array}{c}\text { Group } \\
\text { D }\end{array}$ & Subendocardial region & $145(59)$ & $85(12)$ & $131(6)$ \\
\hline $\begin{array}{c}\text { Group } \\
\text { E }\end{array}$ & Subepicardial region & $78(0)$ & $89(10)$ & \\
\hline
\end{tabular}

The numbers show all vessels and ( ) shows the number of vessels having intimal changes.

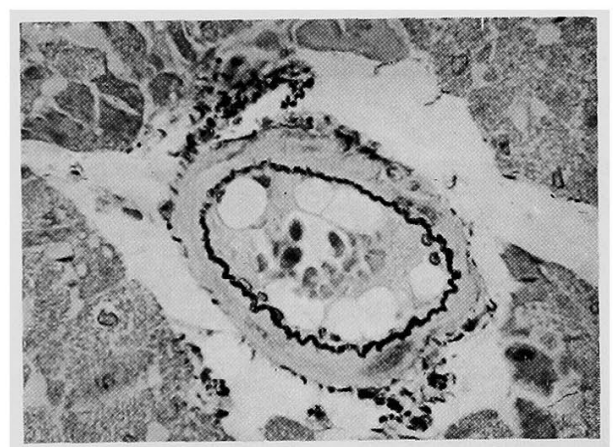

Fig. 13. A foam cell and slight intimal hyperplasia are noted. Elastica Van Gieson's stain; $\times 690$.

frequent in group $\mathrm{A}$ and less so in groups $\mathrm{D}$ and $\mathrm{E}$ (between groups $\mathrm{A}$ and $\mathrm{D}$; $p<0.05$, between groups $\mathrm{A}$ and $\mathrm{E} ; p<0.05)$. In group $\mathrm{A}$ the changes were more frequent in the left ventricle than in the right ventricle $(p<0.01)$, and in the subendocardial regions than in the subcpicardial regions $(p<0.05)$, as 
shown in Table I. Although the same intimal changes were also observed in group $B$, the main intimal change in groups $B$ and $C$ was the formation of foam cell (Fig. 6, 13). No fibrinoid necrosis of vessels was found in any of the rabbits.

Serum cholesterol level determined by Zak-Henry's method ${ }^{12)}$ increased up to 300-500 mg./100 ml. within one week and 2,000-5,000 mg./100 ml. within 2 months when the rabbits (groups $\mathbf{B}$ and $\mathbf{C}$ ) received lanolin and cotton seed oil. No significant changes in serum cholesterol level were found in groups $\mathrm{A}, \mathrm{D}$ and $\mathrm{E}$.

\section{Discussion}

Numerous methods have been reported on the quantitative evaluation of arterio- and arteriolosclerosis. ${ }^{4), 5,13)-20)}$ Quantitative estimation of arteriolosclerosis has been generally attempted by the measurement of the ratio of wall to diameter including the intima. ${ }^{141-16), 20)}$ However, the ratio of wall to diameter may vary very much according to which part of the arterial wall is measured, because the intima is not equally affected longitudinally and circumferentially in the arterial wall and the incidence of arterioles which have the intimal changes may not be the same in each rabbit. For this reason, the ratios of media to diameter were measured excluding the intimal changes. The intimal changes of the vessels were evaluated apart from the changes of the media/diameter ratio, and the frequency of the arterioles having intimal changes were compared in each group.

On histologic preparation the vessels are constricted and vary in response to fixation, staining and embedding; most vessels take the form of an oval and the internal elastic laminae of these vessels wave in various degrees. Many studies have been reported on how much these variations and constrictions of vessels are concerned with the physiological state and how much they are influenced by fixation, embedding, staining and so on. Citters ${ }^{21)}$ suggested that, since the wall of arteries might be greatly thickened during vasoconstriction, the wall to lumen ratio per se could not be a reliable index of medial hypertrophy. According to Okada, ${ }^{4}$ embedding, sectioning and staining resulted in a shrinkage to the specimens from 10 to $30 \%$, with a total reduction in arterial diameter ranging from 5 to $40 \%$, the error due to variations of the rate of shrinkage seemed to be less than $20 \%$, if a large number of arterioles were measured. Andrus $\left.{ }^{16}\right)$ reported that the inner diameter of the same artery varied from 25 to $100 \%$ in accordance with the duration of fixation. Moritz ${ }^{14)}$ stated that the anatomical variations and errors in measurement accounted for differences as great as those which resulted from deliberate variation in methods of tissue preparation 
and varying physiological states.

It would be impossible to equalize the conditions causing constriction and variation of vessels in each rabbit and to speculate the functional state of each vessel. Even though the degree of waving of internal elastic lamina was estimated, the exact ratio of the media/diameter ratio might not be obtained, because most vessels did not take completely round forms. In this study, the media/diameter ratios were calculated, assuming that the forms of vessels were corrected to take the round ones by stretching the internal elastic lamina of the deformed and constricted vessels.

It has been generally accepted that arteriolosclerosis is accelerated by hypertension in selected organs, such as kidneys, spleen and brain. In human beings, however, different opinions have been reported concerning whether arteriolosclerosis in the myocardium is accelerated by hypertension or not. Katheke ${ }^{6}$ reported that arteriolosclerosis in the myocardium was observed in the hypertensive group but not in the non-hypertensive group. Edwards" demonstrated that the small myocardial arteries and arterioles were affected by hypertension. Odel ${ }^{51}$ emphasized that arteriolar changes occurred in the myocardium in the presence of malignant hypertension, although they were less marked than in other organs. Wegelin ${ }^{22)}$ and Shozawa ${ }^{9)}$ concluded that myocardial arteriolosclerosis occurred independently of hypertension. Fishberg ${ }^{2)}$ expressed the idea that terminal arterioles of the myocardium were rarely involved in the arteriolosclerotic process and to only a small extent, and in many instances arteriolosclerosis in other organs were considered insignifcant when compared to that in the kidney. Most qualitative studies ${ }^{23), 24}$ concerned with coronary arterial changes of rabbits in experimental renal hypertension have demonstrated that arteriolosclerosis in the myocardium is observed more frequently in hypertensive rabbits than in non-hypertensive animals.

Present data showed that medial thickening of small arteries and arterioles in the myocardium occurred in the presence of hypertension, and hypercholesterolemia did not influence the increase of the media/diameter ratio. The media/diameter ratio declined linearly in 40 to $110 \mu$. in external diameter and did not show a specific increase. Medial hypertrophy in the arterioles and small arteries has been generally accepted to occur in the presence of hypertension, ${ }^{26)-28}$ although a few reports ${ }^{21)}{ }^{251}$ opposed the belief that medial thickening occurred in hypertension. Recently, Blumenthal ${ }^{20)}$ reported that gencralized arteriolar sclerosis was characterized by thickening of the arteriolar wall, but thickening of the arteriolar wall might be due to an apparent enlargement of the medial smooth fibers or to the appearance of abnormal substances in the vascular wall. 
Intimal changes of the arteries in the myocardium of fat loaded rabbits consisted of formation of foam cells and they could not be found in rabbits which were not fat loaded. Accordingly, the intimal changes which showed endothelial hyperplasia and splitting and proliferation of internal elastic lamina were compared among the non-fat loaded groups $\mathrm{A}, \mathrm{D}$ and $\mathrm{E}$ (these changes have also been found in the small arteries and arterioles of the human heart $\left.{ }^{4}\right)$. The intimal changes were more frequently found in the subendocardial regions of the left ventricles of hypertensive rabbits. When the characteristics of the appearance of intimal changes were considered, it could be suggested that intimal changes of arterioles in the myocardium were accelerated by hypertension but not caused primarily by hypertension; they might be related partially to the circulation of small artery and arterioles which were influenced by the mechanical factors such as intraventricular and intramural pressure increased at the presence of hypertension in the subendocardial regions.

However, the results of the present study might not be applicable to arteriolosclerosis of the human heart. Luisada ${ }^{29}$ stated that although the pathological changes were probably equivalent in different species of animals when the histological picture was similar, the mechanism involved in their production might not be identical in different species.

There have been few reports on the influences of myocardial arteriolosclerosis upon cardiac ischemia. The cause of focal necrosis and infarction not due to main coronary artery disease and the reason for the focal localization of the lesions have been speculatively attributed to mechanical factors, reflex factors, humoral influences and collateral circulation. ${ }^{30)-32}$ However, Matsu$\mathrm{oka}^{33)}$ reported that focal necrosis without main coronary artery disease was due to the lesion of arterioles which supplied the necrotic regions. Linzbach ${ }^{34}$ thought that pre-arteriolosclerosis was the decisive factor in causing coronary insufficiency. Katheke ${ }^{6)}$ expressed the concept that arteriolosclerosis in the myocardium was an important factor of coronary insufficiency in cardiac hypertrophy without main coronary artery disease. Recently Estes ${ }^{35)}$ and Fulton ${ }^{36)}$ demonstrated that a functioning subendocardial network would obviously provide a potential source of collateral blood flow in obliterative disease of the coronary vessels. More systematical research is necessary to investigate both the pathologic role of arteriolosclerosis in the myocardium and the factors which accelerate the development of myocardial arteriolosclerosis.

\section{REFERENCES}

1. Luisada, A. A.: Cardiology. McGraw-Hill Book Co., New York, Toronto, London, Bd. 3, p. 10-12, 1959. 
2. Fishberg, A. M.: Hypertension and Nephritis. Lea \& Febiger, Philadelphia, 4th. ed., p. 298, 1954.

3. Schroeder, H. A.: Hypertensive Disease. Lea \& Febiger, Philadelphia, p. 179, 1953.

4. Okada, R., Murao, S., Saito, M., and Ueda, H.: Jap. Heart J. 3: 13, 1962.

5. Odel, H. M.: Arch. Int. Med. 66: 579, 1940.

6. Kathke, N.: Beit. Path. Anat. 115: 405, 1955.

7. Edwards, J. E.: An Atlas of Acquired Disease of the Heart Vessels. W. B. Saunders Co, Philadelphia, London, p. 705, 1961.

8. Mitchell, J. R. A. and Schwartz, C.J.: Arterial Disease. Blockwell., Oxford, p. 113, 1965.

9. Shozawa, T.: Tr. Soc. Path. 47: 897, 1958 (in Japanese).

10. Kawaguchi, H.: Chiba Med. Soc. 9: 293, 1931 (in Japanese).

11. Takeuchi, J., Takeda, T., Uchida, E., Okada, R., and Shintani, F.: Jap. Heart J. 4: 69, 1963.

12. Zak, B.: Am. J. Clin. Path. 27: 583, 1957.

13. Furuyama, M.: Tohoku J. Exper. Med. 76: 388, 1962.

14. Moritz, A. R. and Oldt, M. R.: Am. J. Path. 13: 679, 1937.

15. Kernohan, J. W., Anderson, E. W., and Keith, M. N.: Arch. Int. Med. 44: 395, 1929.

16. Andrus, F. C.: Am. J. Path. 12: 635, 1936.

17. Lober, P. H.: Arch. Path. 55: 357, 1953.

18. Young, W., Gofman, J. W., Taudy, R., Malamud, N., and Waters, E. S. G.: Am. J. Cardiol. 6: $288,1960$.

19. Horman, R. L., Brown, B. W., Gore, I., Mcmillan, G. C., Paterson, J. C., Pollak, O. J., Roberts, J. C., and Wissler, R. W.: Circulation 22: 1137, 1960.

20. Blumenthal, H.: Cowdry's Arteriosclerosis. 2nd ed., Charles C. Thomas, Springfield, p. 193, 1967.

21. Citters, R. L., Wagner, B. M., and Rushmer, R. F.: Circulat. Res. 10: 668, 1962.

22. Wegelin, C.: Schweiz. Med. Wschr. 74: 57, 1944.

23. Fujii, J.: Jap. Circulat. J. 21: 653, 1957 (in Japanese),

24. Matsuoka, M.: Nagasaki Med. J. 36: 351, 1961.

25. Short, D.: Brit. Heart J. 28: 184, 1966.

26. Anderson, W. A. D.: Pathology. 4th ed., St. Louis, C. W. Mosby, p. 554, 1961.

27. Boyd, W.: Textbook of Pathology, 7th ed., Lea \& Febiger, Philadelphia, p. 516, 1961.

28. Smirk, F. H.: High Arterial Pressure, Charles C. Thomas, Springfield, p. 312, 1957.

29. Luisada, A. A.: Cardiology. McGraw-Hill Book Co., New York, Toronto, London, p. 15-20, 1959.

30. Horn, H., Field, L. E., Dach, S., and Master, A. M.: Am. Heart J. 40: 63, 1950.

31. Friendenberg, C. K. and Rorm, H.: J.A.M.A. 112: 1967, 1939.

32. Gross, H. and Sternberg, W. H.: Arch. Int. Med. 64: 249, 1939.

33. Matsuoka, M. and Ide, H.: Tr. Soc. Path. 49: 707, 1960 (in Japanese).

34. Linzbach, A. J.: Virch. Arch. 314: 534, 1947.

35. Estes, E. H., Entman, M. L., Dixon, H. B., and Hackel, D. B.: Am. Heart J. 71 : 58, 1966.

36. Fulton, W. F. M.: Brit. Heart J. 26: 1, 1964. 